\title{
Evolución de los distribuidores de bases de datos
}

\author{
José María Angós Ullate \\ Universidad de Zaragoza \\ Centro de Documentación Científica \\ José Antonio Salvador Oliván \\ Universidad de Zaragoza \\ Ciencias de la Documentación e Historia de la Ciencia \\ María Jesús Fernández Ruíz \\ Ayuntamiento de Zaragoza \\ Centro de Documentación
}

\subsection{Resumen}

Análisis de la evolución de los distribuidores de bases de datos (hosts) desde 1970 hasta el presente. Se realiza un estudio en profundidad del host Dialog para mostrar los hitos más relevantes de su historia. Se realiza una comparación entre los hosts Dialog y Orbit-Questel para demostrar que la feroz competencia existente en este mercado es la principal razón que explica la desaparición de muchos hosts. (Autores)

Palabras clave: Hosts. Bases de datos en línea. Distribuidores de bases de datos. Historia. Evolución. Dialog. Questel. Orbit.

\subsection{Abstract}

Analysis of the evolution of the database vendors (hosts) from 1970 to the present. An in-depth analysis of Dialog Host has been done to show the more relevant events in this history. A comparison between the Questel-Orbit and the Dialog hosts is carried to demonstrate that the fierce competition is the major reason for the disappearance of many previous hosts. (Authors)

Keywords: Hosts. Online Databases. Database vendors. History. Market evolution. Dialog. Questel. Orbit. 


\section{Introducción}

En este trabajo se describe el cambio, la transformación, que han tenido los distribuidores de bases de datos desde sus comienzos, en los años 70, hasta la actualidad, mayo de 1998. En él se destacan y describen de forma cronológica aquellos sucesos que nos han parecido más relevantes y que han ido marcando los hitos fundamentales en su transformación. El estudio del distribuidor de bases de datos más importante del mundo, el host conocido actualmente como Dialog, nos ha permitido llevar a cabo nuestro proyecto.

\section{El nacimiento de una industria: la distribución de bases de datos (hosts)}

Antes de enumerar cronológicamente los cambios que ha tenido el host Dialog, cabe resaltar que el negocio de las bases de datos está, como cualquier industria, sometida a una competencia feroz, en la que priman los beneficios por encima de todo. Por este motivo, se ha producido en esta industria una gran cantidad de "nacimientos y muertes". Como ejemplo de lo ocurrido a muchos hosts, se relata a continuación una breve historia comparativa de los hosts Dialog y Questel-Orbit, que nos sirven para describir de forma fehaciente la historia acontecida a los distribuidores de bases de datos.

\section{La historia de Questel-Orbit}

La historia de Orbit comienza en 1960 cuando el gobierno del Sur de California adjudicó a la empresa System Development Corporation (SDC) un contrato con la U.S. National Library of Medicine (NLM) para construir un edificio informatizado donde residiera el servicio de información online de la Biblioteca. En 1972 se acabó de desarrollar el software, al que se le llamó sistema de recuperación ORBIT, llegando a constituir el primer servicio comercial de bases de datos online.

SDC registró el sistema de búsqueda con el nombre SDC ORBIT, permitiendo en ese momento acceso a las bases de datos Medline y ERIC (Educational Resources Information Center). El equipo de ingenieros que estuvieron desarrollando ORBIT incluía a Carlos Cuadra, quien más tarde desarrolló STAR, un sistema de gestión de bases de datos. El término ORBIT era el acrónimo de Online Retrieval of Bibliographic Information Timeshared, debido a que las búsquedas en esas fechas se hacían en procesos batch, es decir, se hacían las preguntas al sistema y este, en un proceso posterior, no en tiempo real, las procesaba y devolvía los resultados.

En 1974, finalizó el contrato entre SDC y NLM. Después de la separación, la versión de NLM del software de ORBIT, llamado Medlars/Elhill, permaneció 
durante años igual y todavía hoy en día se usa en NLM. Por otra parte, SDC continuó desarrollando y mejorando ORBIT, y a mediados de 1970, negoció un contrato con la compañía inglesa Derwent, incorporando la Base de Datos World Patents Index, que fue una exclusiva de ORBIT durante 10 años y todavía hoy se puede consultar en este host.

En 1980, la casa central de SDC, Burroughs, se unió con Sperry para formar Unisys. En 1986, Unisys vendió ORBIT Search Service a Robert Maxwell, una multinacional británica de información y comunicación que había ampliado sus intereses en Norteamérica. ORBIT se unió a Pergamon Infoline, un host de servicios en línea que ofrecía una gran cantidad de bases de datos relacionadas con las empresas y los negocios. En estos momentos, la compañía pasó a denominarse Pergamon ORBIT Infoline y la sede central de ORBIT se trasladó de California al área metropolitana de Washington DC. Durante este periodo en que fue propiedad de Maxwell, el principal objetivo y empeño estaba dedicado a desarrollar el software ORBIT y recolectar bases de datos, incorporándose a ORBIT algunas características propias del sistema y bases de datos de Infoline.

En 1989, Maxwell añadió a su imperio de publicidad y comunicaciones un nuevo servicio en línea norteamericano, el sistema BRS (Bibliographic Retrieval Services), proveedor fundamentalmente de bases de datos médicas, farmacéuticas y de negocios. ORBIT y BRS se comercializaron juntos bajo el nombre de Maxwell Online. Originalmente se pretendió que las bases de datos de BRS y ORBIT se ofrecieran bajo un sistema de búsqueda nuevo y mejorado, pero eso nunca ocurrió porque en 1991 falleció Robert Maxwell, y este hecho provocó el colapso de su imperio. En ese momento, se decidió que había que cambiar de nombre, y la compañía pasó a denominarse InfoPro Technologies, una división de MacMillan Publishing. Durante esta época, se decidió también que más que intentar ofrecer un supermercado de bases de datos, sería más aconsejable comercializar el servicio de búsqueda a la audiencia más devota de ORBIT, que en esos momentos eran los profesionales e investigadores que trabajaban en tecnología y propiedad intelectual. Se introdujeron mejoras como PowerSearch, un multifichero único, que agrupaba las bases de datos de patentes y que introdujo la posibilidad de identificación de duplicados de patentes, satisfaciendo de esta manera la demanda de los investigadores en ese campo.

En 1994, una compañía en línea Francesa, Questel, una división de France Telecom, compró la parte de ORBIT a InfoPro Technologies, y ORBIT pasó a llamarse Questel-Orbit. La gran colección de bases de datos de patentes de ORBIT complementó la de Questel, que ya tenía una cobertura importante en temas científicos, de marcas y de patentes. Este acontecimiento abrió las puertas del mercado norteamericano a la compañía francesa, puesto que incorporaba a los clientes que tenía ORBIT.

Scire. 4 : 1 (ene.-jun. 1998) 99-116. 
Questel-Orbit hizo grandes esfuerzos por desarrollar sistemas que proporcionaran recursos y herramientas de búsqueda comunes para facilitar el acceso a todas las bases de datos, y en la actualidad, continúa trabajando para proporcionar recursos de información de calidad en áreas como la propiedad intelectual, la investigación científica y los negocios internacionales.

\section{La historia de DIALOG}

Los acontecimientos más relevantes y significativos en la historia de Dialog son los siguientes:

\section{Año 1972}

Nace Dialog con una única base de datos, ERIC que contiene materiales educativos recogidos por el Educational Resources Information Center del U.S. Department of Education. El acceso se realiza a través del network Tymshare compatible con terminales que operaban a velocidades de 10, 15 o 30 caracteres por segundo. Posteriormente, se proporcionó acceso a otra base de datos del gobierno, NTIS, producida por el U.S. Department of Commerce's National Technical Information Service para informar sobre los resultados de centros de investigación y desarrollo financiados por el gobierno. Los comandos de búsqueda de DIALOG estaban llenos de “@” y “\#”. Eran años en los que el término "usuario final", crítico en nuestros días, todavía estaba por inventar.

\section{Año 1973}

En el mes de mayo, aparece la revista Chronolog, que informa a los clientes de las novedades y mejoras que iban produciéndose en el sistema. Se añaden en un primer momento la base de datos PsycINFO (llamada al principio Psychological Abstracts Database), y posteriormente, las bases de datos Agricola (llamada CAIN, con 200.000 registros), INSPEC (llamada Science Abstract) y, finalmente, la base de datos de negocios comercializada por la empresa: ABI/INFORM (Abstracted Business Information).

\section{Año 1974}

Se incorpora la primera base de datos de Predicast, un fichero llamado Chemical Market Abstracts (CMA) que contenía 30.000 referencias, y poco después una segunda base, Electronic Market Abstracts (EMA). CMA-EMA fue la precursora de lo que hoy conocemos como PTS PROMT, que ahora contiene más de 3 millones de registros, muchos de ellos en texto completo. También este año se añadió COMPuterized Engineering inDEX, llamada COMPENDEX, que es la base de datos más importante en temas de Ingeniería. Otra base de datos histórica, la más importante en Química, se añadió en la primavera de este año, la de American Chemical Society's CA Condensates, que más tarde se llamó CA 
SEARCH. Esta era una base de datos grande, incluso para la época, con 800.000 registros, conteniendo en la actualidad más de 11 millones de registros. En el verano de 1974 se añadió una base de datos del Institute for Scientific Information (ISI), la Social Science Citation Index (más tarde Social Scisearch), con lo que la cobertura en ciencias sociales aumentó enormemente.

\section{Año 1975}

Se incorpora otra base de datos del ISI, Scisearch, y que al igual que Social Scisearch, presentan la característica única e importante de poder buscar por referencias citadas. A mediados de este año se añadió BIOSIS PREVIEWS, producida por el BioSciences Information Service; inicialmente con 850.000 registros en todos los campos de las ciencias de la vida, y que ha ido creciendo hasta disponer de más de 8 millones actualmente. También se añadió este año la primera de las bases de datos de patentes producida por IFI/Plenum, a la que se le llamó CLAIMS (de Class Code, Assignee, Index Method Search). Originalmente cubría 350.000 patentes químicas de Estados Unidos; hoy contiene más de 2 millones de patentes.

\section{Año 1981}

Se introduce en el lenguaje de interrogación el comando MAP, que permite ahorrar tiempo y dinero al poder guardar términos de búsqueda, tales como sinónimos químicos, números de registro CAS o números DUNS, encontrados en uno o más registros en línea y que se necesitan incluir en la estrategia de búsqueda de otras bases de datos.

\section{Años 1982-1986}

Sigue creciendo el número de bases de datos y la mejora de órdenes del sistema.

\section{Año 1987}

En febrero de este año se anuncia una nueva línea de productos de información en CDROM (Compact Disc Read-Only Memory) de Dialog, siendo la base de datos ERIC la primera en ser ofrecida en este formato. El Dr. Roger Summit, presidente de Dialog, justifica este hecho manifestando lo siguiente: "con el mercado empezando a aceptar esta tecnología, su aplicación a productos Dialog OnDisc es una evolución natural para nosotros". La tecnología CDROM ofreció a las bibliotecas, instituciones académicas, empresas, etc., la posibilidad de realizar localmente infinidad de búsquedas a un coste fijo.

En Marzo se ofrece la información más actualizada en la base BusinessWire, donde las noticias se actualizan cada 15 minutos. Esto se consigue porque Dialog ha creado un nuevo software de actualización que proporciona el acceso a las 
noticias más importantes de negocios, solamente minutos después de que el suministrador haya realizado la transmisión electrónica.

En Abril se introduce una interfaz que permite buscar información biomédica mucho más fácil: Dialog Medical Connection. No existen costes mensuales ni coste mínimo por subscripción. Se trata de una amplia colección de bases de datos que cubren las áreas de medicina, salud, biología, medicamentos, y otras ciencias de la vida. Esta herramienta está diseñada para los profesionales que quieren encontrar sus propias respuestas, pudiéndose utilizar con menús o con comandos, y constituye el primer intento serio de acercar la información al usuario final.

En Mayo se crea el servicio First Release con el objetivo de ofrecer noticias inmediatas. Reuters se añade a BusinessWire para ofrecer actualizaciones cada 15 minutos, y el número de bases de datos en texto completo aumenta.

En Junio la versatilidad de INSPEC mejora con la adición de nuevos índices para datos numéricos y químicos. Es un índice fundamental para realizar búsquedas de componentes de una sustancia o sistemas y subsistemas de materiales, algo que resultaba imposible de hasta ese momento.

En Octubre, finalmente, llega lo que todos esperábamos y pedíamos desde hace años: Dialog OneSearch. Ya se puede buscar en más de una base de datos a la vez sin tener que reintroducir cada término de búsqueda o ejecutar una estrategia que previamente habíamos salvado. Por fin se podía buscar en varias bases de datos a la vez con un solo comando. No sólo podíamos comparar resultados entre diferentes ficheros (igual que hacíamos con DialIndex), sino que podíamos modificar los términos de búsqueda, combinarlos y mostrar los resultados. Podíamos hacerlo con 20 bases de datos a la vez.

\section{Año 1988}

Comienza el año con una sorpresa: la nueva capacidad del sistema Dialog para ofrecernos imágenes. La base de datos Trademarkscan-Federal es la primera en ofrecer imágenes gráficas en línea, digitalizadas por Thomson \& Thomson, de las marcas registradas de Norteamérica. Para ello, se añade al software de recuperación Dialoglink en su versión 1.2 la nueva capacidad de conectar a Dialog y visualizar o guardar las imágenes.

En Febrero, se inicia el servicio con nueva velocidad de acceso: a 2400 baudios para los usuarios de Estados Unidos. En Marzo se añade la base de datos más completa del mundo en información sobre patentes y su estado legal, INPADOC/Family and Legal Status, que hasta ese momento era sólo accesible a través del host Pergamon Infoline. 
En Junio, se siguen añadiéndo bases de datos de texto completo, destacando sobre todo The Computer Database, que proporciona el texto completo de 50 revistas. Durante el mes de Julio, se añade la tercera base de datos del Institute for Scientific Information (ISI), Arts \& Humanities Search, que cubre de manera multidisciplinar el campo de las artes y humanidades; esta base contiene en cada registro las referencias citadas y cubre las 1300 revistas más importantes del mundo.

El mes de Agosto trae una auténtico bombazo: Knight-Ridder Business Information Services Inc. compra Dialog Information Services Inc. a Lockheed Corporation en un acuerdo firmado el 11 de Julio de 1988. Efectivamente, como promete su presidente Roger K. Summit, Dialog continuó operando sin interrupción y mejorando sus servicios.

En Octubre, Dialog intenta aumentar su cobertura en información económica y de negocios de Europa, en un intento de disminuir la ventaja que le lleva el distribuidor europeo DataStar, y para ello añade la base de datos Kompass Europe, un directorio de más de 210.000 compañías europeas.

Cada vez más preocupados por dar la información en cuanto ésta se produce, Dialog ofrece en el mes de Noviembre la base de datos PTS PROMT (noticias de negocios e industria internacional) con actualización diaria. Además, la base de datos Dissertation Abstracts Online, que hasta ese momento sólo recogía tesis norteamericanas, empieza a indizar también tesis europeas.

\section{Año 1989}

El comienzo del año trae la incorporación de la base de datos Pascal, hasta entonces accesible en el host Telesystemes, muy importante en cuanto a cobertura de literatura científica y técnica desde 1973. También se añade otra base de datos con imágenes químicas: Heilbron, que proporciona la identificación de sustancias químicas, propiedades físicas y químicas y literatura gris.

En Mayo de este año el sistema incorpora la utilidad de Profile, que permite la personalización de Dialog a nuestras necesidades, y ya es posible enviar imágenes por Dialmail. La ventaja de esta opción es el bajo coste de conexión a Dialmail (12 \$/hora) mientras se transfieren los registros con imágenes. Respecto a las fuentes en texto completo, se añaden más de 120 nuevas revistas en texto completo a la base de datos Trade \& Industry Asap y 6 revistas más a PTS Newsletter Database.

En Agosto, Dialog anuncia su primer producto para Macintosh, Image Catcher, que es un accesorio de escritorio que permite mostrar, imprimir y salvar imágenes encontradas en Dialog mientras se usa nuestro propio software de comunicaciones. 
En Septiembre, la política de Dialog de acercar el sistema al usuario final para captar mayor número de clientes se hace evidente. Puesto que la forma más sencilla y amigable de hacerlo es por medio de menús, la compañía pone en marcha Dialog Homebase, un sistema de acceso asistido por menús. Este mes, además, se satisface otra de las demandas de los usuarios de Dialog: ¿cuánto habría costado una búsqueda si se desconecta accidentalmente el equipo del sistema?. Desde ahora, si eso ha ocurrido, Dialog informa del coste realizado hasta la desconexión, cuando se vuelve a conectar con el sistema.

En Octubre, se proporciona a Beilsten Online, la versión electrónica del Beilstein Handbook of Organic Chemistry desde 1779 (350 volúmenes en su versión impresa). Beilsten Online es la base de datos de Química Orgánica más grande del mundo y, además, contiene datos revisados de los compuestos orgánicos que incluye. Con Beilstein Online llega una nueva utilidad: la posibilidad de búsquedas de estructuras en forma gráfica. Este tipo de búsqueda está basada en el lenguaje ROSDAL (Representation of Organic Structured Descriptions Arranged Linearly), y para dibujar los compuestos se utiliza el software $M O L$ KICK, producido por SOFTRON GmBH. Este programa convierte lo dibujado en una cadena de tipo ROSDAL que se envía como pregunta a Beilstein utilizando el comando QS (Query Structure). En este mes se produce un terremoto de potencia 7.1 en la escala de Richter, en la Bahía de San Francisco (17-10-89), que interrumpe el servicio durante unas pocas horas, pero que, afortunadamente, no produce ninguna pérdida de datos.

En Noviembre, el fichero Papers contiene ya cuatro periódicos en texto completo. Aparecen, por fin, datos sobre empresas españolas recogidas en una base de datos de relevancia mundial como es Kompass Europe. Aproximandamente 16.800 registros de compañías españolas se añadieron a las más de 200.000 compañías europeas que recoge esta base de datos.

En Diciembre, dos años y dos meses después de aparecer OneSearch, surge la una nueva herramienta que lo complementa y que aumenta considerablemente la eficiencia en la recuperación de información: identificar y borrar registros duplicados entre las diferentes bases de datos utilizadas. Era una antigua reclamación de los usuarios, ya que estos nuevos comandos del sistema permiten seleccionar únicamente los registros pertinentes sin obtener —ni, por tanto, pagar- aquellos registros que salen duplicados en otra base de datos. Desde este mes, la base de datos Medline en formato CDROM se actualiza mensualmente.

\section{Año 1990}

Este año es un poco flojo en cuanto a novedades relevantes, pero Dialog sigue aumentando la colección de bases de datos, algunas de ellas en texto completo, y la base de datos Papers incorpora nuevos periódicos. La colección de 
bases de datos en CDROM aumenta. En Junio se hacen mejoras en los operadores de proximidad, permitiendo la utilización de múltiples operadores $\mathrm{N}$ (near). En Noviembre, Dialog se convierte en el primer servicio online que da acceso en línea a U.S. Copyright, una base de datos que contiene información sobre propiedad intelectual, marcas registradas y patentes. En Diciembre, se produce un gran avance: se puede utilizar el comando Expand en DialIndex, lo que permite revisar hasta cien ficheros por nombre de revista, nombre de compañía, autor, etc. Durante este año Dialog ejerce una acción legal contra el Chemical Abstracts Service debido a que no les permite distribuir los registros de su base de datos $C A$ SEARCH con resumen, mientras que a otros hosts si se lo permite (STN y Questel); perdieron el juicio, y todavía siguen sin proporcionar los resúmenes.

\section{Año 1991}

En Enero, aparece un nuevo fichero, el Dialog Journal Name Finder, que contiene el nombre de todas las revistas (JN) indizadas en las bases de datos de Dialog. Su principal utilidad es que permite la identificación de qué base de datos de Dialog tiene una cobertura más amplia de una determinada revista.

En Febrero, aparece una nueva manera de buscar a través de Dialog Menus. Esta característica permite el acceso a las 220 bases de datos más populares de Dialog, con una guía paso a paso que asegura el éxito al usuario más inexperto en los comandos del sistema; por medio de pantallas con menús el sistema va preguntando y mostrando ejemplos para realizar la búsqueda.

En Marzo se incorpora la base de datos Japan Technology, con información sobre el desarrollo e investigación tecnológica realizada en Japón; aspecto importante ya que en Estados Unidos siempre ha existido un interés por los avances tecnológicos e industriales producidos en ese país, con lo que se satisfacen en parte las exigencias de bastantes de sus usuarios. El fichero ofrece resúmenes en inglés de los artículos recogidos entre más de 500 revistas científicas, técnicas y de negocios japonesas. En el mes de Abril, se incorpora otra base de datos japonesa, y ahora le toca el turno a Teikoku Databank (Japanese Companies).

En Junio, debido al gran número de periódicos en texto completo que se ofrecen ya en sus bases de datos, Dialog decide crear dividir Papers, y crea Paper 2 . En la primera hay 20 periódicos, y en la segunda 9. Desde entonces se han creado cuatro subdivisiones: periódicos del Noreste, Región Central, Sureste y Oeste.

En Octubre, se añade un nuevo fichero, Dialog Company Name Finder, basado en el nombre de las compañías (CN) que están indizadas en las bases de datos de Dialog. Permite la identificación de qué base de datos de Dialog tiene información sobre una determinada compañía (de entre los 12 millones de compañías que existen en unos 100 ficheros en Dialog). 
En Noviembre, el presidente y creador de Dialog, Roger K. Summint, después de 25 años, deja la presidencia a Patrick Tierney. En Diciembre, MEDTEXT proporciona acceso al texto completo de una colección de prestigiosas revistas médicas: The New England Journal of Medicine y The Journal of the American Medical Association (JAMA). Dialog crea una nueva base de datos para ayudar en las búsquedas de nombres de productos: Dialog Product Name Finder, que permite localizar aquellas bases en las que aparecen los productos. Desde este mismo mes, las bases de datos de Dialog pueden ser consultadas a través de la red Internet, siendo el coste de conexión de $3 \$$ /hora.

\section{Año 1992}

En Enero, Dialog celebra su 20 aniversario. Durante este período se había pasado de ofrecer una sola base de datos a ofertar más de 400 , además de productos en formato CDROM, interfaces basados en menús y productos especializados como Dialog Business Connection. Sigue añadiendo más información europea, punto débil en la información distribuida por Dialog, al incorporar la base de datos Agence France Presse International French Wire que proporciona perspectivas europeas de noticias sobre política, economía, conflictos sociales, cultura, ciencia y deportes (los artículos, incluyendo los términos índice, están en francés). En Septiembre las revistas a texto completo ofrecidas por Dialog alcanzan los 2500 títulos, y se introduce un nuevo método de envío de información: Dialog Source One, que ofrece el envío inmediato de documentos sobre ingeniería en texto completo.

\section{Año 1993}

En Febrero, se ofrece un nuevo comando, Rank, que posibilita obtener tendencias o análisis estadísticos de los resultados de búsqueda. Este comando extrae los términos del campo especificado y los muestra de manera ordenada, de mayor a menor frecuencia. En Marzo, se amplia la cobertura de información japonesa con la base de datos JAPIO producida por Japan Patent Information Organization que incluye resúmenes en inglés.

En Abril, se produce la noticia más significativa del año: Dialog (compañía filial de Knight-Ridder Inc.) compra Data-Star, líder de servicios de información en línea en Europa, a Motor-Columbus, una empresa Suiza. ¿Por qué esa compra? Para fortalecer su posición internacional y, a la vez, deshacerse de un peligro creciente. Los servicios que proporciona Data-Star son el acceso a unas 300 bases de datos, de las que 150 no estaban accesibles en Dialog, particularmente colecciones de bases de datos muy importantes en el área Europea: noticias, directorios médicos y farmacéuticos y negocios. También desde este mes, la base de datos U.S. Patents Fulltext proporciona las patentes norteamericanas a texto completo desde 1974, con un total de 1,4 millones de registros. 
En Septiembre, Dialog y BT North America firman un acuerdo para dar un servicio de telecomunicaciones con la última tecnología y al precio más bajo posible. La velocidad de acceso oscila entre 9.600 y 14.400 baudios, siendo el coste de 11.40 \$/hora.

En Noviembre, termina de desarrollarse el software de telecomunicaciones Dialogklink, diseñado para el entorno Windows. Aparece también una nueva manera de buscar en el sistema Dialog: el comando Target, que mejora la relevancia de los resultados de búsqueda y disminuye el "ruido" sin que resulte necesario tener ningún conocimiento del lenguaje de comandos o de la lógica booleana. Se introducen los términos de búsqueda separados por un espacio en blanco, y a través de un análisis estadístico del número de veces que aparecen dichos términos, proporciona los registros que son relevantes para el tema buscado. Los resultados de la búsqueda pueden obtenerse por fax o a través del correo electrónico del usuario.

\section{Año 1994}

Dialog decide transformar su sistema de ordenadores centralizado en un sistema cliente/servidor más rápido, con mejores prestaciones y con un sistema de búsqueda de información más flexible, aunque la conversión al nuevo sistema tardará aún varios años.

En Febrero, la base de datos más importante de información de patentes, Derwent World Patent Index, añade imágenes a sus registros desde 1992. En Abril, la conexión a Dialog vía Internet ya es posible mediante telnet a Dialog.com (telnet 192.132.3.254).

En Julio, aparece la versión de Dialoglink para ordenadores Macintosh. Durante el verano de este año, siguen apareciendo más bases de datos de marcas registradas y periódicos en texto completo, y los productos en CDROM siguen aumentando.

\section{Año 1995}

A partir de este año, deja de utilizarse la marca Dialog, y la empresa aparece ya como KnightRidder (la empresa que lo compró en 1988); la decisión de este cambio de nombre viene motivada por el lanzamiento del nuevo producto $K R$ Probase. Este sistema permite tener en nuestro ordenador todas las herramientas de las que se dispone cuando nos conectamos a Dialog en línea así como los manuales que nos ayudan a elegir la base de datos correcta para hacer las búsquedas. Un segundo producto será lanzado próximamente: KR BusinessBase, que cubre más de 10 millones de compañías de todo el mundo. Un tercer producto, KR ScienceBase para el World Wide Web, recibió una acogida entusiástica en la conferencia de la American Chemical Society. Este sistema consiste en una 
nueva línea de búsqueda intuitiva para científicos; desarrollado junto con profesionales de la información, la colección de preguntas y sus correspondientes estrategias de búsqueda proporcionan un acercamiento a la búsqueda asistida inteligente, y revoluciona la manera en que los científicos acceden y usan la literatura académica. Se está desarrollando KR ScienceBase para distintas disciplinas y plataformas, puesto que la gran popularidad de Internet entre los científicos hace que sea una elección con un futuro muy prometedor.

En el mes de Julio, se introduce la herramienta Custom Dialog: QuickStart, que permite incluso al usuario en línea más inexperto localizar exactamente la información que precisa. KR Information junto con Advanced Research Technologies (ART) ha desarrollado un conjunto de aplicaciones que combinan la experiencia de un experto en búsquedas, el sistema Windows y la potencia de Dialog. Se pone en marcha el web de Knight Ridder Information, cuya dirección es la siguiente: http://www.dialog.com.

En el mes de Septiembre, el Chemical Abstracts Service se amplía para cubrir también documentos electrónicos e incluye el Uniform Resource Locator (URL). En Octubre, KR Probase se pone a disposición de los usuarios de los Estados Unidos y Canadá, permitiendo así el acceso a las bases de datos de DataStar por medio de un sistema de entorno Windows muy fácil de usar. Con esta herramienta el profesional de las búsquedas, que no tiene que conocer nada sobre el host DataStar, puede controlar la selección de la base de datos y formular sus preguntas. En Noviembre aparece la nueva versión de Dialoglink para Windows 95. En estos momentos, el sistema contiene casi 400 bases de datos accesibles en línea.

\section{Año 1996}

En Enero se da acceso en Dialog al New York Times, con lo que se alcanzan las 150 fuentes de noticias en texto completo de todo el mundo ( 55 son diarios de los Estados Unidos) y en Febrero, se lanza la herramienta de búsqueda $K R$ ScienceBase anunciada el año anterior, y que es accesible vía Internet en la WWW.

En Marzo, se lanza KR OnDisc para Windows, y la empresa crea su web comercial (http://www.dialogweb.com/), en el que se puede encontrar toda la información sobre Dialog y sus productos. En Mayo, la aparición del nuevo comando IDPAT para identificar duplicados de patentes nos permite superar la revisión manual que exigían los resultados de las búsquedas de patentes. IDPAT es diferente del comando $I D$ porque cada base de patentes de Dialog tienen una perspectiva única y presenta los datos de manera diferente.

En Junio llega a Dialog UnCover, un gran recurso de información. Contiene artículos desde 1988 al presente, de unas 17.000 revistas multidisciplinarias pero 
centrándose en Ciencias y Ciencias Sociales. El envío de referencias por correo electrónico es la forma más utilizada por los usuarios.

En el mes de Julio se lanza en Europa el Intellectual Property QuickStart, un producto novedoso que permite realizar búsquedas eficaces a los que no están familiarizados con la búsqueda de referencias en el campo de la propiedad intelectual. La búsqueda se lleva a cabo por medio de una interfaz Windows, con iconos que guían en la búsqueda de datos. La selección de la base de datos se realiza mediante software, de manera transparente y sin que nos demos cuenta, apareciendo los resultados en la pantalla.

En Noviembre, se incorporan mejoras en KR ProBase, al poder salvarse los registros de manera que se puedan usar en Intranet usando formato HTML, o en formato RTF para usarlos en procesadores de texto como Word u otros. En Diciembre, DataStar permite el acceso a todas sus bases de datos en el Web http://www.datastarweb.com, y proporciona una demostración de cómo funciona. En este mes se produce un cambio de presidente, sustituyendo Jeffeery S. Galt a Patrick J. Tierney

\section{Año 1997}

En Enero se cumplen las bodas de plata (25 aniversario) de Dialog. Se logra un acuerdo entre Dow Jones, Financial Times Information y Knight-Ridder Information para desarrollar la colección en línea sobre negocios más grande del mundo.

En Abril, llega la base de datos Humanities Abstracts Full Text que indiza unas 400 revistas en inglés. El texto completo corresponde a 95 publicaciones desde 1995, cubriendo la base de datos desde 1994. Este hecho viene a cubrir la laguna existente en cuanto a cobertura de información en el campo de las humanidades.

En Mayo, ya es posible buscar en Dialog a través de la Web. La dirección es la siguiente: http://www.dialogweb.com. El servicio añade las ventajas propias de este entorno, entre las que se pueden citar que los registros tienen fuentes más vistosas y pueden guardarse como TXT o en HTML, pero también se padecen algunos de sus inconvenientes, como la lentitud en la carga de las páginas.

En Junio, se da acceso a lo mejor de Dialog con Dialog Select, la nueva interface Web con 250 bases de datos. El usuario final, sin necesitar ningún conocimiento previo sobre la realización de búsquedas en Dialog, tiene en sus manos un recurso que puede darle resultados al instante. Simplemente introduciendo los términos de búsqueda, se obtienen los resultados. Por supuesto, trabajando detrás, el sistema se encarga de usar las características apropiadas: OneSearch, Rank, detección de duplicados, etc. Sólo hace falta lógicamente una conexión a 
Internet y los navegadores Netscape o Explorer (versión 2.0 o superior). $K R @$ Site ofrece acceso Intranet a las bases de datos KR Ondisc usando un visualizador Web (versiones 3.0 o posterior). Se trata es un producto diseñado para proporcionar un acceso rápido a los CDROM de KR OnDisc montados en un dri$v e$, torre o jukebox remoto. Se puede acceder desde diferentes plataformas como Windows, Macintosh o Unix.

En Septiembre, el acuerdo firmado en Enero entre Finacial Times Information, Dow-Jones y Knight-Ridder ha cristalizado en la creación de la base de datos World Reporter, que nos pone el mundo de las noticias de negocios en nuestras manos. Combina fuentes de calidad con información de gran actualidad a partir de las noticias proporcionadas por los periódicos y revistas de negocios líderes de todo el mundo, así como de las newswire. Proporciona el texto completo para la mayoría de los artículos que están en inglés. El diario Cinco Días, el más relevante de España en temas económicos y financieros está accesible en Knight-Ridder Information (DataStar).

En Noviembre, M.A.I.D. (Market Analysis and Information Database) compra Knight-Ridder Information por 420 millones de dólares. Nace la nueva compañía Dialog Corporation. Ahora que el mercado se estaba acostumbrando a KR, vuelve la marca Dialog. El presidente de MAID, Daniel Wagner toma el relevo de Jeff Galt. La nueva compañía lanza Profound, que proporciona información sobre negocios de las publicaciones líderes de todo el mundo y que puede accederse por Internet con una interfaz en Windows muy fácil de usar. Todos los productos de Profound utilizan InfoSort, el mecanismo de indización de MAID (www.dialog.com). Profound es el servicio de negocios en línea diseñado para enviar los datos que necesitamos para tomar decisiones, cada día, sin sobrecarga de información. En Profound se utiliza el sistema de indización propietario InfoSort, con los datos indizados por contexto, asegurando la precisión de la búsqueda. Cada ítem que entra en la base de datos es indizado de acuerdo con un conjunto común de términos de negocios y con un tesauro. El usuario puede usar después el mismo criterio para buscar los ítems en cualquiera de las bases de datos. Esto asegura una velocidad y exactitud de búsqueda sin competencia en otros sistemas. La nueva empresa pretende seguir trabajando con las bases de datos de KR, potenciando las soluciones Web. A partir de la tecnología LiveWire, desarrollada por MAID pretenden desarrollar una nueva generación de productos con tecnología push para distribuir información en tiempo real.

\section{Año 1998}

Desaparece la revista Chronolog en papel, y sólo queda la versión electrónica en el web, que aparece con una periodicidad bimensual. Sin embargo, se edita 
una nueva revista trimestral Dialect, que cubre todos los aspectos de información de la industria Europea.

A principios de año, aparece en Dialog la base de datos TradeMarkScan®Spain. El fichero contiene aproximadamente 1.250.000 registros de marcas solicitadas en España.

Se cambia la forma de facturar en Dialog Select, y a partir de ahora sólo se paga por los documentos encontrados (cada título visualizado a $0.25 \$$ ). Asimismo, Newspapers y Newswires se proporcionan gratis. Se siguen añadiendo periódicos a Papers (75 periódicos USA en texto completo), CDROM y también bases de datos de marcas registradas, incluidas las de toda la Unión Europea.

Durante este último año se han producido grandes cambios en la conceptualización de la gestión de la información. El concepto de intranet ha pasado de la experimentación a la realidad. Sólo en los Estados Unidos, aproximadamente el $70 \%$ de las 500 compañías más importantes ya han puesto en marcha intranets para la gestión del conocimiento interno de la organización. La intranet proporciona la posibilidad de analizar, filtrar e interpretar los datos en los que los usuarios se basan para tomar decisiones. Ya no se busca información, se busca conocimiento. Dialog se suma al movimiento de las intranets y proporciona varios servicios nuevos para evitar la sobrecarga de información:

- Envío de información relevante a nuestra intranet a precio fijo. Dialog Corporation ofrecerá recursos para crear nuestras propias bases de datos personalizadas, usando InfoSort.

- Archivos personalizados con alertas en directo.

- Indización personalizada para hacer una gestión del conocimiento integrada.

Actualmente, la información en Dialog Corporation es unas 50 veces la del World Wide Web, más de 6 billones de páginas de texto en unas 900 bases de datos, pero el contenido en sí mismo no es suficiente. El usuario necesita herramientas de rápido acceso a los datos más relevantes y pertinentes. Nuestro tiempo es muy valioso, y los interfaces y herramientas de búsqueda deben ayudarnos a encontrar los mejores recursos sin pérdida de tiempo. El usuario requiere que los productos estén diseñados para mantenernos offline y que cuando sea absolutamente necesario conectarse online, gastemos el mínimo de tiempo en el sistema.

\section{Conclusiones}

Los distribuidores de bases de datos ofrecen mucho más que un flujo amorfo de datos contenidos en bases de datos individuales. Por medio de una combina- 
ción de índices especializados, características de búsqueda propias y únicas, múltiples medios de búsqueda, opciones de envío y un servicio de alta calidad, documentación y entrenamiento, los hosts transforman los materiales que reciben de los proveedores de bases de datos de la misma manera que un fabricante de coches reprocesa y ensambla los componentes que recibe de sus proveedores.

El primer servicio de valor añadido que nos proporcionan se puede caracterizar con la frase "el total es mayor que la suma de las partes". Lo esencial para la utilización efectiva de la información es acceder a esa información. Un sistema que permitiera a los usuarios describir con palabras y frases normales el contenido de los documentos que desean encontrar era impensable en los siglos anteriores al nuestro. Detrás de esta capacidad están unos índices muy amplios, índices para cada palabra de la base de datos, que son creados y recargados por los ordenadores cada vez que el fichero es actualizado. La mayor parte de los recursos de almacenamiento y potencia de cálculo están orientados al mantenimiento de estos índices. Este proceso va más allá de la simple distribución o creación de bases de datos; es la sinergia de muchos elementos que conjuntamente proporcionan el "valor añadido" que los hosts nos ofrecen.

El segundo valor que proporcionan es la posibilidad de acceder desde nuestro propio lugar trabajo a una amplia variedad de bases de datos. Han reunido la mayor cantidad de conocimiento disponible en la historia de la humanidad, y lo han puesto a disposición de cualquier usuario en formato electrónico.

Un tercer valor es proporcionar documentos primarios online. Con respecto al texto completo, pocos de nosotros nos damos cuenta que, por ejemplo, Dialog tiene más noticias en texto completo que el servicio NEXIS y más información financiera en texto completo que las Dow Jones News. Centrándonos en este host, Dialog tiene muchas características de búsqueda novedosas como OneSearch, identificación de duplicados, Map, Report, etc. que permiten la integración efectiva de la información de múltiples bases de datos. Para que el usuario final se sienta cómodo en el sistema, ha creado productos como Dialog Business Conection, Dialog Medical Connection, First Release (noticias continuamente actualizadas) y Papers (la colección de periódicos de Los Estados Unidos). Además, ha creado Dialog OnDisc, Dialog Alerts y Dialmail, que nos permiten elegir la combinación que mejor se adapte a nuestras necesidades de información. Otras de las utilidades y herramientas de gran utilidad desarrolladas por Dialog han sido KR Probase, KR ScienceBase, KR Busines Base, DIALOG Select, InfoSort, etc.

Por último, cabe preguntarse ¿hacia dónde vamos? Pensamos que hacia una tecnología push, en la que mediante sistemas expertos se resolverán las necesidades de información que tengan los usuarios finales, con una relación servi- 
cio/coste mejor. Todo ello usando, por un lado, el soporte de comunicaciones de Internet y los servicios web como interfaz de usuario, y, por el otro, las bases de datos en CD-ROM en redes Intranet, compartiéndolas entre diferentes campus o empresas situadas en lugares próximos o remotos.

\section{Bibliografía}

The Dialog Chronolog. Dialog Information Services. Palo Alto. California (USA). 1 (1973).

The Dialog Chronolog. Dialog Information Services. Palo Alto. California (USA). 2(1974).

The Dialog Chronolog. Dialog Information Services. Palo Alto. California (USA). 3 (1975).

The Dialog Chronolog. Dialog Information Services. Palo Alto. California (USA). $9: 1$ (1981).

The Dialog Chronolog. Dialog Information Services. Palo Alto. California (USA). 15: 2, 3, 4, 5, 6 y 10 (1987).

The Dialog Chronolog. Dialog Information Services. Palo Alto. California (USA). 16 : 1 , 2, 3, 6, 7, 10 y 11 (1988).

The Dialog Chronolog. Dialog Information Services. Palo Alto. California (USA). 17 : 1 , $5,8,9,10,11$ y 12 (1989).

The Dialog Chronolog. Dialog Information Services. Palo Alto. California (USA). 18 :6, 11 y 12 (1990).

The Dialog Chronolog. Dialog Information Services. Palo Alto. California (USA). 19: 1, 2, 3, 4, 6, 10, 11 y 12 (1991).

The Dialog Chronolog. Dialog Information Services. Palo Alto. California (USA). $20: 1$ y 9 (1992).

The Dialog Chronolog. Dialog Information Services. Palo Alto. California (USA). 21:2, 3, 4, 9, y 1 (1993).

The Dialog Chronolog. Dialog Information Services. Palo Alto. California (USA). 22 : 2 , 4 y 7 (1994).

The Dialog Chronolog. Dialog Information Services. Palo Alto. California (USA). 23:1, 7, 9 y 11 (1995).

Chronolog. European Edition. Knight Ridder Information Ltd. London (UK); 1996;

(Enero, Febrero, Marzo, Mayo, Junio, Julio, Noviembre, Diciembre).

Chronolog. European Edition. Knight Ridder Information Ltd. London (UK); 1997; (Enero, Abril, Mayo, Septiembre, Noviembre).

Chronolog. The Dialog Corporation.

URL=< http://library.dialog.com/chron/1998/9801/index.html>

Chronolog. The Dialog Corporation.

URL=<http://library.dialog.com/chron/1998/9803/index.html >

Chronolog. The Dialog Corporation.

URL $=<$ http://library.dialog.com/chron/1998/9805/index.html >

Scire. 4 : 1 (ene.-jun. 1998) 99-116. 
116 José María Angós, José Antonio Salvador y María Jesús Fernández

Questel Actualites. Telesystemes Questel. Paris. (Jun., 1984-93).

Communique. Questel Orbit, France Telecom Group. 1-14 (1994-98)

Scire. 4 : 1 (ene.-jun. 1998) 99-116. 